\title{
Chapter 13 \\ Tackling Social Exclusion and Marginality for Poverty Reduction: Indian Experiences
}

\author{
Sukhadeo Thorat
}

\begin{abstract}
This chapter examines changes in poverty in combination with changes in income and the character of income growth for multiple socio-religious groups in India. The extent to which income growth has been pro-poor was also evaluated. Income growth was compared between agricultural and non-agricultural livelihoods, between rural and urban areas, and across ethnic, caste, and religious groups. The analysis found that poverty was reduced at a lower rate for Scheduled Tribes, Scheduled Castes, and Muslims, who suffer from social exclusion and discrimination, than for the rest of the society. These groups have a history of high levels of poverty in India, and compared to mainstream society members these groups typically own less agricultural land, have less access to private non-agricultural economic activities, and are more dependent on wage employment.
\end{abstract}

Keywords Poverty $\bullet$ Social exclusion $\bullet$ Marginality $\bullet$ Pro-poor growth $\bullet$ India

\subsection{Introduction}

Empirical evidence on changes in poverty has indicated that "poverty reduction has most benefitted people living close to the poverty line rather than those at the very bottom of income distribution" (von Braun et al. 2009, 5). The most extreme and persistently poor generally have common features, such as a lack of assets and education, but they also often belong to certain social groups-typically groups distinguished by race, color, social origin (caste), religion, or geographical location. They suffer from chronic poverty that is often passed on to consecutive generations.

\footnotetext{
S. Thorat $(\square)$

Centre for the Study of Regional Development, School of Social Sciences,

Jawaharlal Nehru University, New Delhi, India

e-mail: thoratsukhadeo@yahoo.co.in 
While poverty is closely associated with the economic condition of the poor, the persistence of poverty is a feature particularly linked with marginality.

We have a fairly good basis of understanding the economic factors associated with poverty and hunger (von Braun et al. 2009). Extreme poverty is caused in part by limited ownership or access to agricultural land or business opportunities, the potential to develop education and skills, and stable employment. Poverty is also caused by the lack of participation in governmental control over poverty alleviation efforts. Therefore, the poor are frequently landless or are small-producers or farmers in marginal areas for agriculture, or are wage-labor dependent, or have limited skills and education, or are unemployed or else are engaged in lowincome occupations. Within the general category of the poor are people belonging to certain social groups that generally suffer more from intense poverty than their societal counterparts, indicating that in addition to economic factors there are often constraints associated with social or cultural identity that contribute to their condition (Thorat 2010).

Presumably there are specific reasons for higher rates of poverty among certain social groups. Although it may appear that the factors that cause poverty are similar for both the poor in general and certain social groups, the "channels of causation" that determine higher poverty rates for certain social groups are different in some respects. Studies have found that in these cases poverty is often closely linked with social exclusion - the social processes through which some groups are denied equal access to sources of income, employment, education, and participation in decisionmaking processes. Groups that are socially excluded are not like the rest of the poor. They are also disadvantaged by unavoidable circumstances and as a result are deprived of many of the benefits of socio-economic development. Social exclusion deprives people of choices and opportunities to escape from poverty and denies them a voice to claim their rights (Thorat et al. 2005). Poverty outcomes are greatly affected by the exclusion of women, ethnic, religious, indigenous, and caste groups based on social norms, and values and customs within families, communities, or markets. Sen (2000, 28-29) argued that "unfair exclusion and/or unfair inclusion" (access based on discriminatory terms and conditions) with respect to opportunities reduces entitlement and the capability to enhance personal well-being, thus aggravating poverty among the socially excluded groups.

Drawing from the Indian experience, in this chapter I discuss changes in poverty among multiple social groups. I have attempted to bring some insight on the possible linkages between social exclusion and marginalization among certain ethnicities, castes, and religious groups. India is in many ways a unique case with a high diversity of social groups identified by ethnicity, caste, or religion for which the government has developed specific policies, making it highly suitable for an analysis of social marginalization. I examined changes in poverty in combination with changes in income and the character of income growth for multiple socio-religious groups. Specifically, I examined to what extent income growth has been "pro-poor." The degree of pro-poor income growth was compared between agricultural and nonagricultural livelihoods, between rural and urban areas, and across ethnic, caste, and religious groups. 


\subsection{Some Insights from Literature on Poverty, Social Exclusion, and Growth}

\subsubsection{Growth, Inequality, and Poverty Linkages}

The first systematic treatment of the relationship between growth and poverty was made by Kuznets (1955), who argued that long-term secular behaviors of inequality follow an inverted U-shaped pattern, with inequality increasing during the early stages of growth in developing countries and then decreasing after some time. Empirical studies that followed Kuznets' pioneering work found evidence that in addition to growth in per capita income, income distributions are also determined by other socio-economic factors such as: population growth rates, income (or worker) shares in non-agricultural economic sectors, urbanization levels, education, and government interventions (Adelman and Morris 1973; Paukert 1973; Ahluwalia 1976a, b; Papanek 1978; Tsakloglou 1988). Tsakloglou (1988) found that the rate of population growth was positively related to income inequality, whereas educational levels, the extent of government activity, and rates of GDP growth per capita had negative relationships with inequality. Other studies have found that while the share of non-agricultural sectors in overall economies is important, increases in employment in more productive sectors and the productivity of traditional sectors are critical for reducing poverty (Paukert 1973; Ahluwalia 1976a, b; Kraay 2004; Hull 2009).

Research by Ravallion (2001, 2009; Ravallion and Datt 2002; Ravallion and Chen 2003) brought further insight into the relationships between economic growth, inequality, and poverty, but with distinct results. For 80 countries during most of the 1980-2000 period, Ravallion (2009) reported that there was little or no correlation between changes in inequality and rates of economic growth, and concluded that growth tended to be roughly distribution neutral. The authors also found that the rates of poverty decline tended to be less propoor in countries where initial inequality was higher compared to those where it was lower.

In Ravallion's view (2009), certain inequalities not only generate higher poverty in the immediate term, but also impede future growth and poverty reduction, including social exclusion, discrimination, travel restrictions, constraints on human development, lack of access to financial and insurance support, and corruption. All of these inequalities perpetuate poverty by limiting the prospects for economic advancement among certain segments of the population. "More rapid poverty reduction would require more growth, a more pro-poor pattern of growth, and success in reducing the antecedent inequalities that limit poor people's access to economic opportunities" (Ravallion and Chen 2003, 185). These insights indicate that participation in growth and poverty reduction are dependent on a number of factors that include not only growth in per capita income, but also a host of socio-economic inequalities that limit economic opportunities for the poor. 


\subsubsection{Pro-poor Growth}

The concept of pro-poor growth has been a subject of discussion in the context of "inclusive growth." Ravallion and Chen $(2003,94)$ argued that "pro-poor growth is any growth in the mean income that benefits poor." Kakwani argued that pro-poor growth has limitations as "it would encompass the vast majority of growth episodes so long as poverty declines" (Kakwani 2000, 68). It is therefore argued that for growth to be pro-poor, it should benefit the poor proportionately more than the non-poor.

This brings the focus on the distribution of outcomes of growth among the poor and non-poor. In this context a distinction is often drawn between strongly pro-poor and weakly pro-poor impacts of growth, the former relates to situations in which incomes rise proportionally faster for the poor than for the non-poor, and the latter for a situation in which growth benefits the poor considerably less than the nonpoor (Lipton 1991). Moreover, the tradeoffs between changes in absolute poverty and inequality between rich and poor are meaningful (Grinspun 2009). What happens to inequality in income distribution and the distribution of income around the poverty line in the process of economic growth are important determinants of the relative "pro-poor" qualities of growth (and not the distribution of income among the upper classes).

Osmani (2005) took the definition a step further. He argued that the true test of being pro-poor is the existence of policies biased in favor of the poor with reference to the country's past record of poverty reduction, and defined pro-poor growth as growth processes that reduce poverty more than past policies. The benchmarks in this case will be country specific.

To overcome the limitation of Osmani's criterion, three alternative criteria of "pro-poorness" have been proposed: (1) that the share of income growth for the poor exceeds their existing share, (2) that the poor's share in incremental income surpasses their share in the population, and (3) that the share of the poor in incremental growth exceeds some international norm (Grinspun 2009). Thus, pro-poor growth is achieved when the poorest of the poor benefit from the growth and not just the poor nearer to established poverty lines. To the extent that the pro-poor qualities of growth involve not only the reduction of absolute poverty, but also its rate of change for poor and the share of the poor in incremental income gains, it really focuses on the tradeoffs between changes in poverty and inequality in income distribution in the process of growth. A set of comprehensive criteria for "pro-poor" growth include:

- achieves absolute reduction in poverty

- benefits the poor proportionately more than the non-poor

- raises income proportionally faster for the poor than the non-poor

- reduces poverty beyond some country specific benchmark

- benefits the poorest and not just the poor near poverty lines

- increases the income of the poor in excess of their share of the population

- increases the income of the poor beyond some international norm 


\subsubsection{Social Exclusion and Persistent Poverty}

Literature on poverty and socially excluded groups has identified that factors such as social exclusion and discrimination perpetuate persistent poverty. There is extremely limited empirical work on how social exclusion and discrimination contribute to poverty among excluded groups. We have limited understanding about the processes involved in "exclusion induced poverty." Social exclusion in general, and particularly socioeconomic exclusion, are the processes through which groups are denied access to rights or economic and social participation in society. Exclusion may occur directly (unfavorable exclusion), or through deliberate government policies (active exclusion), and through unintended circumstances (passive exclusion), or through the inability of some social groups to respect the rights of others (constitutive relevance) (Sen 2000, 28-29). Social exclusion aggravates poverty directly by denying access to opportunities channeled through market and non-market transactions, and indirectly by adversely affecting economic growth. In so far as exclusion and discrimination are involved in the denial of access to resources, employment, education, and common facilities certainly impoverish the lives of individuals belonging to excluded groups. Addressing "exclusion induced poverty" will require policies that provide safeguards against market and non-market discrimination of excluded groups. To base policies on empirical insights, it is necessary to better understand how market and non-market discrimination aggravate poverty both directly and indirectly.

\subsection{Poverty Changes in India by Socio-religious Groups 1983-2005}

The incidence of household poverty and changes therein between rural and urban areas were examined for multiple socio-religious groups during the period from 1983-1984 to 2004-2005 using a simple measure of poverty called the Head Count Ratio (HCR). For each group the poverty level was also examined by livelihood source. In rural areas these included: "self-employed in agriculture" (SEAG) or farmers, "self-employed in non-agriculture" (SENA), "agricultural wage labor" (AGLA), and "non-agricultural wage labor" (OTLA). For urban areas the livelihood groups included: "self-employed" (SEMP), "wage/salaried" (RWSE), "casual labor" (CALA), and "other" (OTHER).

The socio-religious groups in the analysis included four social groups: the "Scheduled Tribes" (ST), "Scheduled Castes" (SC), "Other Backward Classes" (OBC), and "other castes" (non-ST/SC/OBC), and three religious groups, the "Muslim minority" (MM), "Hindus," and "other religious groups" (ORM). The ST are indigenous ethnic groups that are often physically and socially isolated. The SC traditionally suffered from social exclusion and discrimination associated with the caste system. The government treats Muslims as a targeted minority for 
special policies. Data on the OBC were not separable from the "other castes" in the 1983-1984 database and therefore they were both included together with "other castes" for some analyses.

\subsubsection{Socio-religious Groups}

First, general changes in poverty were examined and afterwards the data were disaggregated by livelihood, socio-religious group, and between rural and urban areas. Between 1983 and 2005 overall rural poverty declined at an average rate of $1.9 \%$ per annum, which was equivalent to an $18 \%$ point decline over the entire period. Across social groups the average annual rate of decline in poverty was greatest for the non-ST/SC group (2.1\%), followed by the SC (1.8\%), and ST (1.4\%) groups. In regard to religious groups, rural poverty declined at a slightly higher average annual rate for the Hindus and ORM (both $1.9 \%$ ), than for the MM group $(1.7 \%)$, despite the fact that the latter group has been targeted by government poverty alleviation policies.

During 2004-2005 the HCR poverty levels were persistently higher among the ST households ( $47 \%$ ), followed by the SC (37\%), OBC ( $26 \%$ ), and non-ST/SC/ OBC $(17 \%)$. Although the MM had a higher poverty level (33\%) than the Hindus and ORM groups, they had lower poverty levels than the SC and ST groups. This pattern prevailed during the mid-2000s.

\subsubsection{Livelihood Categories and Socio-religious Groups}

I examined the changes in poverty among livelihood categories by socio-religious group. Among rural livelihood categories the wage labor households were poorer than the self-employed. In 2004-2005 approximately $44 \%$ of the AGLA livelihood households and $33 \%$ of the OTLA households were poor. By comparison the poverty levels for both the SEAG and SENA livelihood households were about $20 \%$.

Rural poverty also declined at higher annual rates for the self-employed livelihoods ( $2.3 \%$ for SEAG and $2.1 \%$ for SENA) than for wage-labor (approximately $1.6 \%$ for both AGLA and OTLA). The decline was slightly less for the AGLA livelihoods than for OTLA. The poverty rates among the SEAG livelihood households differed by socio-religious group. Poverty declined for the SEAG livelihood households among all groups over the study period, but at lower rates for the SC and ST households than the other social groups, and at a lower rate for the MM compared to the Hindus among the religious groups.

During the overall period the SENA livelihood households also experienced declines in poverty among all socio-religious groups, however, the ST and SC SENA households declined at lower average annual rates (about $1.9 \%$ ) compared to all other 
groups $(2.5 \%)$. Among the religious groups the MM declined at a lower average annual rate $(1.7 \%$ ) than the Hindus and ORM households (both about $3.6 \%$ ).

Among the socio-religious groups, poverty declined at the lowest rates for the ST and SC wage-labor livelihood households. In the case of AGLA livelihoods among social groups, poverty declined at an average annual rate of $1.1 \%$ for the ST, $1.5 \%$ for the SC, and $1.7 \%$ for the non-ST/SC group. In the case of OTLA livelihoods among social groups, poverty declined at an average annual rate of $1.2 \%$ for the ST and SC groups, compared to $2.0 \%$ among non-ST/SC households. Thus, for both rural wage labor livelihood categories the ST and SC groups exhibited less poverty reduction than the other social group. In the case of religious groups there were no significant differences in the rates of poverty decline among rural wage labor livelihood households, however, the ORM OTLA households did slightly better than their Hindu and MM counterparts.

\subsubsection{Changes in Income-Monthly Per Capita Expenditures as a Proxy Variable}

I examined changes in household income using "monthly per-capita expenditures" (MPCE) as a proxy value. The National Sample Survey Organisation defines the means of livelihood on the basis of majority income contribution source at the household level. For example, a household is classified as an AGLA household if $50 \%$ or more of its total annual income is derived from agricultural labor. By this criterion the OTHER category of household livelihoods are those whose income comes from two or more sources such that income from each source is less than $50 \%$ of total household income. During the study period the overall MPCE increased at an average rate of $1.2 \%$ per annum. The average per annum percentage increases were nearly the same for all socio-religious groups (1.1-1.3\%). The SENA livelihood households exhibited the highest average annual increases in MPCE $(1.6 \%)$ and the rest of the livelihood groups increased at lower rates (around $1.0 \%$ ). Urban OTHER livelihood households experienced the highest average per annum increase at $2.0 \%$.

Among the social groups the ST and non-ST/SC had relatively higher MPCE increases than the SC group. Among the religious groups the Hindus and ORM groups had relatively higher rates of MPCE increase than the MM. The SC and MM SENA households lagged behind all other socio-religious groups in the rates of MPCE increase.

There was not much difference in the rates of MPCE increase of SEAG livelihood households among the socio-religious groups. Among the rural wage labor livelihoods the AGLA households increased at an average per annum rate of $1.1 \%$ compared to $0.8 \%$ for OTLA households. With the exception of the MM households, whose MPCE increased at slightly higher rate $(1.6 \%)$, there were no substantial differences in the average annual MPCE rates among the socioreligious groups. 


\subsubsection{Changes in Poverty, Income, and the Elasticity of Poverty Reduction}

During the 21-year period between 1983 and 2005, rural poverty declined at an average rate of $1.9 \%$ per annum, while the MPCE grew by an average rate of $1.2 \%$ per annum. This suggests that increases in consumption expenditures were correlated with reduced poverty. The growth in consumption expenditures was lower, just as poverty was reduced at a moderate rate. The overall elasticity value of poverty reduction with respect to MPCE growth was 2.3 in 2004-2005.

The fact that the average per annum growth in MPCE was more or less the same across socio-religious groups, and that the ST, SC, and MM groups that were initially the poorest also lagged behind to the other groups in poverty reduction, indicate that economic growth has not been pro-poor. This assertion was supported by the different elasticity values of poverty reduction with respect to MPCE during the 1983-2005 period. The growth elasticity with respect to poverty reduction values were 2.6 for the non-ST/SC group, 2.0 for SC, 1.6 for ST, and 1.7 for the MM group. Therefore, economic growth brought less reduction in poverty for groups suffering from greater poverty compared with those experiencing less poverty.

\subsubsection{Livelihood by Socio-religious Groups}

\subsubsection{Rural Self-Employed Households}

The results indicated that per unit growth in income among self-employed livelihoods brought greater declines in poverty for agricultural (SEAG) than non-agricultural (SENA) livelihoods. This was clearly supported by much higher growth reduction elasticity (3.4) for SEAG households compared to SENA (2.2) households. The differential decline also suggests that rural agricultural growth has been more pro-poor than non-agricultural growth. Given the facts that the bulk of the poor live in rural areas and that growth has the potential to benefit poor farmers, more rural agricultural investment with a clear focus on marginal and small scale farmers is likely to alleviate poverty. To improve the pro-poor performance of growth in the non-agricultural sector requires policy measures that will change policy orientation towards small producers and businesses in such a manner that future growth will increase the income of poor self-employed producers and business households.

\subsubsection{Rural Wage-Labor Households}

The patterns are somewhat different with respect to the pro-poor character of agriculture and non-agricultural sector growth for wage laborers, who constituted the 
bulk of the poor in rural areas. The distributions of gains from increased farm income were not shared equally by SEAG and AGLA livelihood households. AGLA livelihoods experienced the lowest poverty decline, had the highest HCR poverty level, and the lowest rate of MPCE increase of any livelihood category. Although growth in small-scale agriculture is likely to reduce poverty for SEAG households, it may not perform for wage laborers as many SEAG households provide their own labor. The growth of labor intensive agriculture may result in greater employment or higher-wages and thus reduce poverty for wage laborers.

\subsubsection{Socio-religious Groups}

This pattern of greater improvement among self-employed versus wage-labor agricultural livelihoods was observed across all socio-religious groups. Despite similar increases in MPCE poverty declined at differential rates, indicating differential poverty reducing impacts of growth on MPCE across the various groups. Poverty among the ST, SC, and MM groups declined at lower per annum rates compared to the other groups. What explains this differential reduction in poverty? Increases in MPCE corresponded with lower declines in poverty for the ST, SC, and MM households compared to the other socio-religious groups. This was borne out by the lower poverty reduction elasticity with respect to MPCE for the ST, SC, and MM households, which were 1.6, 2.0, and 1.8 respectively. The elasticity values were 2.6 for the non-ST/SC group, 2.4 for Hindus, and 2.5 for ORM.

The pro-poor character of growth in MPCE also differed for self-employed and wage labor livelihoods across socio-religious groups. In the case of SEAG livelihoods, there was little difference in the rate of MPCE change across social groups. Therefore, the variable elasticity of poverty reduction was associated with unequal outcomes in poverty reduction across socio-religious groups. Growth elasticity values were lower for the ST and SC households among social groups, and for Hindus among religious groups. Similar to SEAG livelihoods, poverty among SENA livelihood households also declined at lower rates for the ST, SC, and MM socio-religious groups compared to the rest. Lower declines in poverty were closely associated with relatively lower increases in MPCE for these groups. The average per annum poverty decline was particularly lower for the SC group. The elasticity value of poverty reduction was also lower for the ST and MM groups. In the case of the SC group, although MPCE increased only marginally they seem to have gone in favor of the poor households in so far as the elasticity of poverty reduction value was the highest of any socio-religious group. This may also mean that the SC nonagricultural production and business activities have higher potential for poverty reduction in rural areas. In the case of the ST and MM groups, lower increases in MPCE as well as lower poverty reduction elasticity with respect to MPCE were linked to lower poverty declines among SENA livelihood households. In the case of the non-ST/SC, Hindus, and ORM groups, both higher average per annum increases and higher elasticity of the MPCE values were linked to higher poverty reduction among SENA livelihood households. 
For wage labor livelihoods, poverty declined among AGLA households at a lower rate for the ST group, followed by the SC, MM, and non-ST/SC groups. Except for a somewhat higher increase for MM households, the per annum increase in MPCE was similar for all groups. Therefore, the lower poverty declines of the ST, SC, and MM AGLA livelihood households were likely linked to the lower poverty reduction elasticity values. The ST, SC, and MM groups seemed to face more constraints in AGLA livelihoods compared to the rest of the groups. The higher poverty declines among AGLA livelihoods for the ORMs and Hindus occurred along with greater increases in both MPCE and poverty reduction elasticity values. In the case of OTLA livelihoods, poverty declined at much lower rates for the ST and SC groups compared to the rest of the socio-religious groups. The lower poverty reduction rates for the ST and SC OTLA livelihoods were accompanied by lower increases in MPCE, as the poverty reduction elasticity values did not differ between them. In the cases of the other social groups, both increased MPCE and relatively higher elasticity values were accompanied by reductions in poverty. In the case of OTLA livelihood MM households the growth in MPCE was an important factor.

\subsection{Urban Poverty}

\subsubsection{Changes in Poverty by Social Groups}

The overall poverty level in urban areas was $26 \%$ in 2004-2005, only about $2 \%$ lower than in rural areas; however, there were notable differences among the socioreligious groups. Unlike in rural areas where poverty incidence was the highest among the ST group followed by the SC, MM, and OBC, in urban areas the SC and MM groups had the highest incidences of poverty. The ST and OBC groups had similar poverty levels, whereas non-ST/SC/OBC among the social groups and ORMs among religious groups had the lowest poverty incidences. For the ST, SC, and MM groups the highest poverty levels were for CALA livelihood households at $58 \%$. The groups with the highest poverty levels among CALA households were the ST and SC, with HCRs of 74 and $67 \%$ respectively. Poverty was also high (40 \%) among the SEMP (self-employed) livelihoods, particularly for the SC, ST, and MM groups. The poverty level was also high (34 \%) among RWSE (wage/salaried) livelihood households of the MM group.

Several interesting features emerged regarding the direction of change across socio-religious groups. During the 1983-2005 period overall poverty levels declined at an average rate of $1.9 \%$ per annum. For the overall period, the lowest average annual poverty reduction rates were observed among the ST (1.1\%) and the MM $(1.4 \%)$, and the highest among the non-ST/SC (2.4\%) and SC (2.0\%) groups. Among religious groups the highest rates of decline were for the ORM $(3.1 \%)$ group, followed by Hindus $(2.1 \%)$, and MM (1.4\%). With regard to poverty reduction rates in the urban sector by socio-religious group, the data were only comparable for the period from 1993-1994 to 2004-2005, because the group classification 
in 1983 was different. Poverty among SEMP livelihood households declined at relatively lower rates for the SC and MM groups compared to the rest. In the case of RWSE livelihoods, poverty declined at much higher average annual rates for the ST (5.4\%) and ORM (4.1\%) groups, followed by the SC, non-ST/SC, and Hindus. The declines were lowest for the MM group $(0.6 \%)$. While the SC group performed badly in poverty reduction for SEMP livelihoods, the rates were better for RWSE livelihoods. The MM group exhibited low poverty reduction among both the SEMP and RWSE livelihood categories during the 1993-2005 period. In the case of CALA livelihood households, the SC and ST groups lagged behind the others. The MM and non-ST/SC groups experienced greater poverty reduction among CALA livelihood households than the rest.

Growth in urban income. During the entire 1983-2005 period urban MPCE grew by an average of $1.8 \%$ per annum for all households, which was significantly higher than in rural areas. Among social groups the highest growth rate was experienced by the non-ST/SC group (1.9\%), while the SC group had the lowest (1.3\%). The ST group was closer to the non-ST/SC group with an average rate of $1.8 \%$ per annum.

Growth, poverty, and elasticity linkages. The overall poverty reduction elasticity value was 1.5 . Among socio-religious groups elasticity values were relatively higher for the ORM (2.04) group, non-ST/SC (1.64), and Hindus (1.61); and lowest for the MM (1.26), SC (1.31), and ST (1.48) groups. Thus, the urban economic growth was less pro-poor with respect to impacts on the MM, SC, and ST groups. The SEMP livelihoods for which comparable data were available exhibited similar patterns, except that the rank order was the ST, followed by MM and SC.

\subsection{Implications for Socially Inclusive Policy}

These results have implications for poverty reduction policies for all socio-religious groups. Before discussing policy issues in India, we need to examine insights from theoretical and empirical literature. In particular it is important to consider literature on the relationships between economic development, poverty, and inequality in income distribution, including recent discussions on inclusive growth and to what extent it addresses the issues of excluded groups.

\subsubsection{Improving Pro-poor Performance of Agricultural and Non-agricultural Growth}

In light of the changes in poverty among social groups during the 1983-2005 period and insights from earlier studies on pro-poor growth, I propose group-specific policy measures. The findings point towards strengthening some existing policies and also developing some new ones. 


\subsubsection{Agricultural Livelihoods}

On the positive side, growth in agriculture has been far more pro-poor than non-agricultural growth. In fact among all livelihood categories the elasticity of poverty reduction with respect to MPCE was highest for SEAG livelihoods, implying that agricultural sector growth has been more effective at reducing poverty among small-scale and marginal producers. Since agricultural sector growth has poverty reducing potential, there is justification for strengthening the observed pattern of growth. There are, however, negative aspects of agricultural growth which would likely benefit from policy change. Agricultural growth did not reduce poverty among AGLA (wage labor) livelihoods in equal measure. The elasticity of poverty reduction with respect to MPCE was much less for AGLA (1.4) livelihoods compared to SEAG (2.3). This is consistent with the facts that AGLA livelihood poverty decreased at a lower rate than any other livelihood category, had the highest HCR value, and had the lowest increase in MPCE.

AGLA livelihood households will benefit more from growth in agriculture only if their employment opportunities or wages increase. Growth in labor intensive medium and large scale agriculture may result in greater wage employment and thus reduce poverty for AGLA livelihood households. Policies that encourage large- and medium-scale producers to cultivate labor-intensive crops and utilize labor-intensive practices have poverty reducing potential. Thus, an overall agricultural growth strategy that addresses both labor intensive production among large and medium-scale producers and continued improvements for small-scale and marginal producer will be more effective at reducing poverty.

Another negative feature of the observed agricultural growth was the limited poverty improvement among the ST, SC, and MM socio-religious groups. Growth elasticity values with respect to poverty were 2.5 for the non-ST/SC and Hindus, 2.0 for the SC and MM groups, and only 1.4 for the ST. Strengthening the position of small-scale producers in general, particularly among the ST, SC, and MM groups is a necessary element of inclusive agricultural sector growth. While employmentoriented policies are necessary for improving AGLA livelihoods in general, special efforts are necessary for the ST, SC, and MM groups, who often suffer from discrimination in rural labor markets (Thorat and Newman 2010).

Based on experiences since the early 1980s, inclusive policy for the agricultural sector would include:

- More labor-intensive agriculture among medium- and large-scale producers

- Focus on small-scale producers

- Special assistance for the ST, SC, and MM small-scale producers

- Special attention for the ST, SC, and MM, AGLA livelihoods

\subsubsection{Rural Non-agricultural Livelihoods}

During the 1983-2005 period rural non-agricultural growth was more pro-poor for wage labor than for self-employed livelihoods. The elasticity value of poverty 
reduction for OTLA livelihoods was 2.0 as opposed to 1.4 for AGLA livelihoods. Limited poverty reduction for the ST and SC OTLA households was associated with lower increases in MPCE. In the case of the non-ST/SC group, increases in both MPCE and elasticity were relevant to poverty reduction.

The non-agricultural sector policy implications are clear. Since the elasticity of poverty reduction was positive and higher for wage labor, and the slow decline in poverty was linked to limited increases in MPCE, measures are necessary to increase rural non-agricultural sector growth. The pro-poor character of growth also needs to be strengthened, because elasticity began to decrease in the 1990s. The pro-poor character of production activities needs to be enhanced, particularly for selfemployed livelihoods, through support and incentives for increasing the profitability of small producers and businesses.

\subsubsection{Group-Specific Policy Measures}

Poverty was reduced at a lower rate for the ST, SC, and MM socio-religious groups, which suffer from social exclusion and discrimination in India. Members of these groups typically own less agricultural land, have less access private non-agricultural economic activities, and are more dependent on wage employment. These groups have higher historical levels of poverty, which has been found to limit poverty reduction. The socio-religious groups with better access to assets and lower historical poverty have done better. This implies that the groups with higher poverty levels and less access to assets and sustainable livelihoods need specific and affirmative action policies.

Among the social groups the ST performed the worst in poverty reduction for both self-employed and wage labor households. The lack of access to agricultural land is generally less of a problem for the ST, about $40 \%$ of ST households were farmers and approximately $40 \%$ of these households were classified as poor. The poverty level among the ST AGLA households was formidably high at $56 \%$ in 2005. Poverty levels associated with tribal agriculture are persistent and higher due to low productivity and income. How to make agriculture more productive in tribal areas is a challenge that has not been addressed effectively.

It appears that a core need is to develop appropriate crops and methods for tribal areas. This will require renewed research efforts on the special needs of agriculture in tribal areas, including the potential for developing tree, flower, fruit, and livestock or dairy production on grazing land. Tribal agriculture has pro-poor qualities, both for SEAG and AGLA livelihoods, as the elasticity values were positive and tended to be higher in good years.

Unlike the ST, the SC group has much less access to agricultural land, and as a result the bulk of the SC households (about $56 \%$ ) were wage labor reliant. Poverty reduction among the SC will depend on employment enhancement. Increased employment opportunities and improved skill and education development will raise employment rates households in both the agricultural and non-agricultural sectors (Dev 2005). 
In the case of the MM group, access to income earning assets was better than for the SC group. More than half of the MM households were engaged in productive enterprises and/or businesses. Policy measures that focus on strengthening the incentives and supporting small-scale enterprises and businesses have potential to reduce poverty for this group.

\subsubsection{Urban Development}

In the case of SEMP livelihoods, all socio-religious groups except the ST exhibited poverty declines with moderate increases or stagnation in MPCE. In the case of the MM group, both income growth and elasticity with respect to poverty were quite low. Approximately $52 \%$ of the urban MM households were engaged in SEMP livelihoods, but MPCE growth was lower and poverty was higher. Approximately one-third of the SC households were engaged in SEMP livelihoods, but this group's MPCE increase was the lowest and its poverty levels highest among the socioreligious groups. In order to accelerate poverty reduction, growth in urban SEMP livelihoods is necessary. A policy focus on small producers and businesses would make growth more pro-poor and inclusive. In the case of RWSE livelihoods, for which we only have data for the 1990s, poverty showed significant declines for the ST and ORM socio-religious groups, followed by the SC, Hindus, and MM. So while the expansion of employment opportunities in urban areas should continue, there is a need to make it more pro-poor, which requires enhancement in education and skill development opportunities among the SC and MM groups. Lastly, the CALA livelihoods, which were the poorest among the three urban livelihood categories, experienced the lowest poverty declines. This was particularly the case for the SC and ST CALA households. Increasing hands-on skill development and the expansion of employment opportunity are the only alternatives for this chronically poor livelihood category.

Open Access This chapter is distributed under the terms of the Creative Commons Attribution Noncommercial License, which permits any noncommercial use, distribution, and reproduction in any medium, provided the original author(s) and source are credited.

\section{References}

Adelman I, Morris CT (1973) Economic growth and social equity in developing countries. Stanford University Press, Stanford

Ahluwalia MS (1976a) Income distribution and development: some stylized facts. Am Econ Rev 66(May):128-135

Ahluwalia MS (1976b) Inequality, poverty and development. J Dev Econ 3:307-342

Dev MS (2005) Pro-poor growth in India: what do we know about the employment effects of growth 1980-2000? Working paper no 161. Overseas Development Institute, London

Grinspun A (2009) Pro-poor growth: finding the Holy Grail, IPC-IC collection of one pagers no 6. International Poverty Centre, United Nations Development Programme, Brasilia 
Hull K (2009) Understanding the relationship between economic growth, employment and poverty reduction. Organisation for Economic Co-operation and Development, Paris

Kakwani N (2000) On measuring growth and inequality components of poverty with application to Thailand. J Quant Econ 16(1):67-79

Kraay A (2004) When is growth pro-poor? Cross-country evidence, World Bank policy research working paper no 3225. World Bank, Washington, DC

Kuznets S (1955) Economic growth and income inequality. Am Econ Rev 45(1):1-28

Lipton M (1991) A note on poverty and sustainability. IDS Bull 22(4):12-16

Osmani S (2005) Defining pro-poor growth. In: IPC-IC collection of one pagers no 9. International Poverty Centre, United Nations Development Programme, Brasilia

Papanek G (1978) Economic growth, income distribution and political processes in LDCs. In: Griliches Z, Krelle W, Krupp H-J, Kyn O (eds) Income distribution and in economic inequality. Campus Verlag/Halstead Press, Frankfurt/New York

Paukert F (1973) Income distribution at different levels of development. Int Labour Rev 108:97-125

Ravallion M (2001) Growth, inequality and poverty: looking beyond averages. World Dev 29(11):1803-1815

Ravallion M (2009) Economic growth and poverty reduction: do poor countries need to worry about inequality? In: von Braun J, Hill RV, Pandya-Lorch R (eds) The poorest and hungry: assessments, analyses, and actions. International Food Policy Research Institute, Washington, DC, pp 179-186

Ravallion M, Chen S (2003) Measuring pro-poor growth. Econ Lett 78:93-99

Ravallion M, Datt G (2002) Why has economic growth been more pro-poor in some states of India than others? J Dev Econ 68(2):381-400

Sen A (2000) Social exclusion: concept, application and scrutiny, Social development paper no 1. Office of Environment and Social Development, Asian Development Bank, Manila

Thorat A (2010) Ethnicity, caste, and religion-implications for poverty outcomes. Econ Polit Wkly XLV(52):18-24

Thorat S, Newman K (eds) (2010) Block by caste: economic discrimination modern India. Oxford University Press, New Delhi

Thorat S, Vanketsan S, Mahamallick M (2005) Human poverty, social exclusion and marginalized groups, Working paper. United Nations Development Programme, New York

Tsakloglou P (1988) Development and inequality revisited. Appl Econ 20(4):509-531

von Braun J, Hill RV, Pandya-Lorch R (eds) (2009) The poorest and hungry: assessments, analyses, and actions. International Food Policy Research Institute, Washington, DC 